
\title{
25 Research Soure \\ A Refined Model of a Typhoon Near-Surface Wind Field Based on CFD
}

\author{
Youtian Yang \\ Beijing Normal University \\ Lin Dong \\ Beijing Normal University \\ Jiazi Li \\ Beijing Normal University \\ Wenli Li \\ Beijing Normal University \\ Dan Sheng \\ Beijing Normal University \\ Hua Zhang ( $\square$ zhanghua2011@bnu.edu.cn ) \\ Beijing Normal University https://orcid.org/0000-0002-0380-9556
}

\section{Research Article}

Keywords: CFD, Near-surface wind field, Wind speed terrain correction, Typhoon disaster

Posted Date: October 25th, 2021

DOl: https://doi.org/10.21203/rs.3.rs-993283/v1

License: (c) (1) This work is licensed under a Creative Commons Attribution 4.0 International License.

Read Full License 


\title{
A Refined Model of a Typhoon Near- Surface Wind Field Based on CFD
}

\author{
Youtian Yang ${ }^{1}$, Lin Dong ${ }^{1}$, Jiazi Li ${ }^{1}$, Wenli Li ${ }^{1}$, Dan Sheng ${ }^{1}$, Hua Zhang ${ }^{2,3, *}$ \\ 1 Faculty of Geographical Science, Beijing Normal University, Beijing 100875, China; \\ 201921051167@mail.bnu.edu.cn(Y.Y.);201921051152@mail.bnu.edu.cn(L.D.); \\ 202021051160@mail.bnu.edu.cn(J.L.);202121051168@mail.bnu.edu.cn(W.L.); \\ 202121051172@mail.bnu.edu.cn (D.S.) \\ 2 School of National Security and Emergency Management, Beijing Normal University, Beijing \\ 100875, China; \\ 3 China Academy of Education and Social Development, Beijing Normal University, Beijing \\ 100875, China; \\ * Correspondence: zhanghua2011 @bnu.edu.cn; Tel.: +86-15120098201
}

\begin{abstract}
Near-surface typhoon wind field simulation is a key method for high-precision typhoon hazard assessment and is of great significance for disaster forecast, loss risk assessment and emergency management. The terrain correction method for regional large-scale wind field simulation has a single correction method, which cannot satisfy the requirements of refined risk assessment. This paper aims to use the accuracy advantage of the fluid dynamics mechanism model (CFD, computational fluid dynamics) in small-scale wind speed simulation and obtain a terrain correction method suitable for regional largescale wind field simulation by extracting the spatial change law of the wind speed under complex terrain. Among them, typical mountains with different cross-sectional shapes and different slopes are used to characterize the undulating terrain, and the CFD model is used to simulate and analyze the wind speed changes on the upwind slope, mountain top area, leeward slope, and downwind area under different initial wind speeds. The wind speed at these locations has a good quantitative relationship with the initial wind speed. Combined with the common building wind load codes in China, the wind speed correction algorithm suitable for large-scale complex terrain has been supplemented and improved. Taking Typhoon 0713 as an example, a near-surface typhoon wind field simulation was performed. Compared with other models, the accuracy of the simulation results of terrain correction by the method provided in this article has increased by 15-19.9\%. The CFD-based typhoon disaster near-surface wind field can more accurately reflect the spatial distribution and intensity of typhoon wind hazards under large-scale complex terrain. It can provide technical support for the loss risk prediction and assessment of forest resources, mountain forestry economy, crops and other disaster-bearing bodies in typhoon disasters.
\end{abstract}

Keywords: CFD; Near-surface wind field; Wind speed terrain correction; Typhoon disaster

\section{Introduction}

Typhoon wind fields can reflect the difference in the spatial range and intensity of typhoon hazard factors (Fang Weihua and Lin Wei 2013). Therefore, typhoon wind field simulation is an important prerequisite for performing typhoon disaster numerical forecasting and loss risk estimation (Li Qian et al. 2005). At present, the hazard assessment of Chinese typhoon hazards is often based on the CMA tropical 
cyclone best path dataset provided by the China Meteorological Administration, which uses the central pressure and maximum wind speed data to simulate wind fields mainly for larger-scale typhoon hazards analysis or to study the evolution of typhoon paths (Ou Jinping et al. 2002). Human and social and economic disaster-bearing bodies that often suffer losses due to typhoon disasters are on the surface, so high-precision typhoon wind field simulation research for near-surface disaster-bearing bodies is of great significance.

The temporal and spatial distribution characteristics of hazard factors are affected by regional differences in the disaster environment. For the hazard factor wind in typhoon disasters, its distribution is greatly affected by the terrain, surface roughness and other surface conditions (Alexander D. 2000). When air flows through hillsides, valleys and other terrains, the wind speed will significantly accelerate or decelerate (Ngo T.T and Letchford C.W 2009 ) At present, most engineering wind load calculations adopt the topographic factor correction method in the wind load codes of various countries (Maharani Y N 2018). To ensure the safety of engineering buildings, the wind load codes of various countries mainly focus on the acceleration effect of the terrain on the wind field; this may also be due to the safety of project site selection, so wind load codes are mostly applicable to areas with slopes below $16^{\circ}$ (Building Structure Load Code [S]. GB50009-2012.). The terrain correction of wind speed based on wind load specifications ignores the deceleration effect of the leeward slope and reduces the uplift acceleration effect of the steep terrain. This assumption will lead to serious underestimation or overestimation of risks when conducting disaster risk analyses.

For wind field simulations of complex terrain, the application of a fluid dynamics mechanism model (CFD, computational fluid dynamics) can accurately reflect the airflow characteristics (Takanori Uchida. 2018) and the flexibility and low cost of numerical simulation make this method the main method to study the law of wind speed changes. Kang Shun et al. (2009) studied the influence of terrain slope, ground roughness, and atmospheric boundary layer on the wind speed of circular steep slope terrain and confirmed the feasibility of CFD for wind farm terrain turbulence. Griffiths et al. (2010) used atmospheric models and CFD to simulate mountain airflows under different slope terrains and verified that the simulation results of the two models were closer when the slope increased. However, due to the complex design of CFD and the large amount of calculation, it is mainly used for microscale airflow field simulation (C. K. Cheng et al. 2005). Scholars have conducted research on the applicability of wind load codes in various countries. Chen Ping (2007) used CFD modeling to simulate and analyze the wind field under two-dimensional terrain with different slopes. Ishihara et al. studied the wind speed distribution of the three-dimensional terrain at the top, side and foot of the mountain (1999), they found that the wind speed near the foot of the windward slope decreased, but the wind speed at the top and side of the mountain significantly increased, and the wind speed at the top increased by 50-60\%. Li Zheng Liang reviewed the impact of the typical terrain on near-ground wind fields (2010), conducted an indepth comparison and analysis of current wind load codes in various countries, and found that the formulation of codes in various countries was basically identical, but the models that proposed the impact of terrain on wind fields were different. Shen Guohui used the CFD simulation method to study the wind field of single and double hills (2016); they found that the acceleration effect at half-hill height above the top of the mountain was weakened, and the acceleration effect of the cross-direction wind was greater than that of the wind direction. In summary, previous studies have confirmed the feasibility of CFD, and some refinements and extensions of wind speed and terrain correction have been proposed. However, due to the large spatial scale affected by typhoon disasters, CFD is difficult to directly apply, so a complete typhoon wind field model combined with CFD has not been formed. 
In summary, the direct use of CFD to perform large-scale typhoon wind field simulations requires a large amount of calculation and is time-consuming, while the accuracy of wind speed simulations with reference to building wind load specifications is insufficient. This paper is based on the CFD simulation of a small-scale complex terrain wind speed field, extracts the wind speed characteristic curve under typical terrain conditions, and combines the wind load specification to improve the large-scale complex terrain influencing factor algorithm, which improves the simulation accuracy of the near-surface typhoon wind field and provides technical support for the numerical evaluation of typhoon disaster risk.

\section{Materials and Methods}

\subsection{Data Source}

(1) Typhoon path data

The historical typhoon sample data come from the CMA tropical cyclone best path dataset released by the China Meteorological Administration. This dataset includes all tropical cyclone information generated in the Northwest Pacific since 1949.

(2) Measured wind speed data at weather stations

The measured wind speed data of meteorological stations come from the daily value datasets of basic meteorological elements of China's national ground meteorological stations.

(3) Basic data

Including DEM data (Aster), land use data (Base on POI (Dong L 2021)).

\subsection{Research methods}

This paper uses CFD to simulate the wind speed of different mountains and extracts the wind speed change rule as the typhoon disaster terrain influence factor algorithm. Based on the CMA typhoon path information, the Holland parametric wind field model with the provisions of the "Building Structure Load Code GB50009-2012" simulates the near-surface wind field of the typhoon disaster and verifies it with the measured data from the weather station.

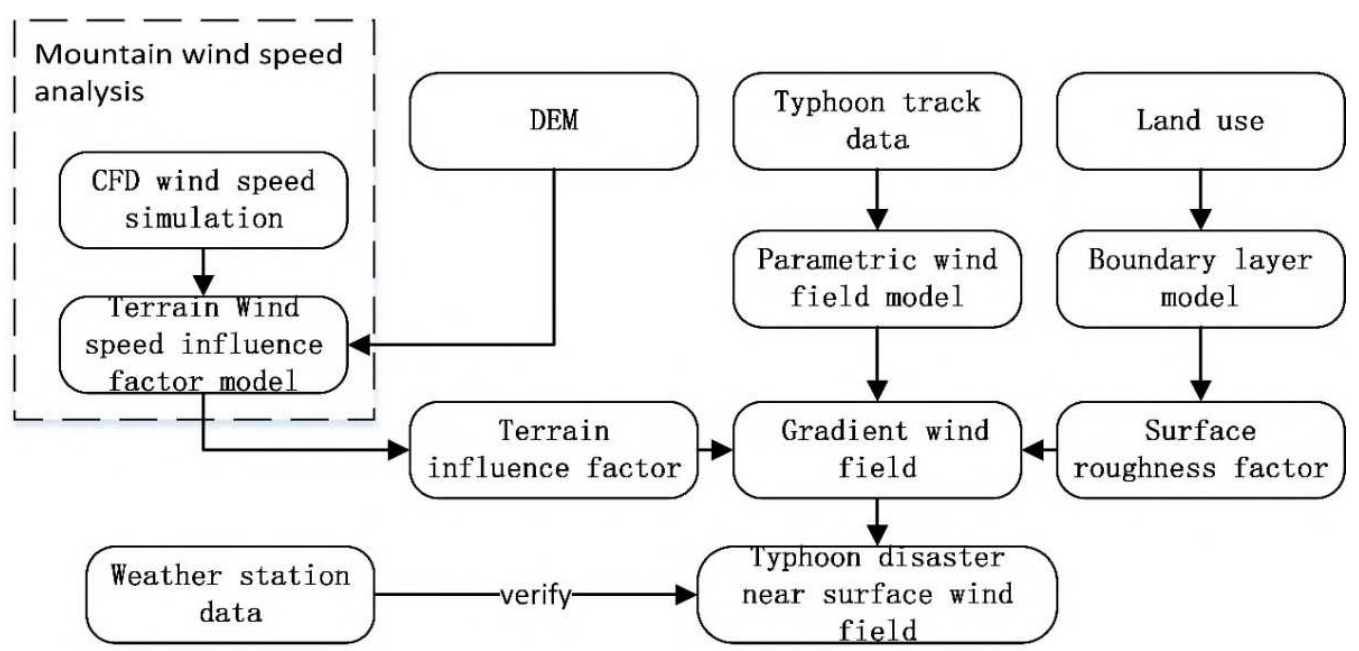

Figure 1. Methodological procedures of the research.

\subsubsection{CFD Technique and Set-up}

To explore the general laws of the changes of different mountain customs, this article sets different slope variation ranges ( $\tan \alpha=0.17 \sim 1$, i.e., the angle is $10^{\circ}, 20^{\circ}, 30,^{\circ} 45^{\circ}$ ), and different crosssectional shapes (parabolic, Gaussian, cosine) ( LI Z L et al. 2016). In total, there are 12 mountain models 
for CFD numerical simulation. Using different initial wind speeds $(15 \mathrm{~m} / \mathrm{s}, 30 \mathrm{~m} / \mathrm{s})$ as the input, test points are arranged on the surface of the mountain to test the simulated wind speed, and the general law of wind speed changing with the ups and downs of the mountain is summarized. Furthermore, the test points are partitioned, and the wind speeds at the foot of the windward slope, the top of the mountain, and the foot of the leeward slope are counted. It is stipulated that $V_{h}=\eta * V_{0}$, where $V_{h}$ is the nearsurface wind speed affected by the terrain, $V_{0}$ is the near-surface free wind speed not affected by the terrain, and $\eta$ is the terrain influence factor, which represents the degree of change in wind speed due to terrain undulations.

\subsubsection{Gradient wind field model}

For typhoon disasters, it is generally believed that when the height above the ground is $300 \sim 550$ $\mathrm{m}$, the wind speed is no longer affected by the surface roughness and topography; i.e., the so-called "gradient wind speed" is reached (Building Structure Load Code). In this paper, a mature and easy-tocalculate Holland parameterized circularly symmetrical wind field is selected to simulate the gradient wind speed (Holland G J 1980), and the wind field equation is:

$$
\begin{aligned}
& V_{g}=\sqrt{\left(p_{n}-p_{c}\right) \frac{B}{\rho_{a}}\left(\frac{R M W}{r}\right)^{B} \exp \left(-\frac{R M W}{r}\right)^{B}+\left(\frac{r f}{2}\right)^{2}}-\frac{r f}{2} \\
& R M W=-18.04 \ln \Delta p+110.22 \\
& B=1.38-0.00184 \Delta p+0.00309 R \mathrm{MW}
\end{aligned}
$$

In Formula (1), $V_{g}$ is the gradient wind speed at a certain point in the typhoon range, $p_{n}$ is the air pressure at the periphery not affected by the typhoon, $p_{c}$ is the central air pressure of the typhoon, $R M W$ is the maximum wind speed radius, $\rho_{a}$ is the air density, $f$ is the Corio benefit parameter, $r$ is the distance between the calculated point and the typhoon center, and parameter $B$ is the shape parameter of the typhoon. The estimation of RMW parameters refers to the empirical formula of Lin Wei et al. (2013) based on JTWC data fitting, and parameter B is calculated using the method proposed by Vickery et al. (Vickery P J and Dhiraj W 2008). These two calculation methods have high applicability in the Northwest Pacific.

\subsubsection{Boundary layer model}

In the near-surface disasters caused by strong winds, ground friction cannot be ignored, and different surface roughness values will further affect the spatial distribution of wind speed. When the pressure field does not change with height, the wind speed mainly depends on the ground roughness and vertical temperature gradient, and the wind speed change law at different heights generally conforms to the exponential law in Formula 4. Here, $a$ is the ground roughness index corresponding to the four types of land use (sea, rural, urban, and metropolitan center), $v_{z}$ is the gradient wind speed at different heights corresponding to different land use types, and $v_{10}$ is the wind speed at a height of $10 \mathrm{~m}$ :

$$
v_{z}=v_{10}\left(\frac{z}{10}\right)^{a}
$$

In summary, using the terrain correction factor calculation model based on the CFD simulation results, high-altitude gradient layer wind field model and boundary layer model, a refined typhoon near-surface wind field model was constructed. 


\subsubsection{Analysis of the Change in Mountain Wind Speed Based on CFD}

In the process of using CFD to simulate the wind speed, since typhoon wind fields are mostly used at a height of 10 meters near the ground in practice, the gradient wind speed reference high speed is set to 10 meters; considering the surface coverage characteristics of multi-vegetation in the mountains of southern China, the surface roughness parameter is set to 0.15 (LOU W J et al. 2016). Figure 2 shows the wind speed changes of the three cross-sectional mountains under different slope scenarios when 15 $\mathrm{m} / \mathrm{s}$ and $30 \mathrm{~m} / \mathrm{s}$ are used as free wind speed inputs:

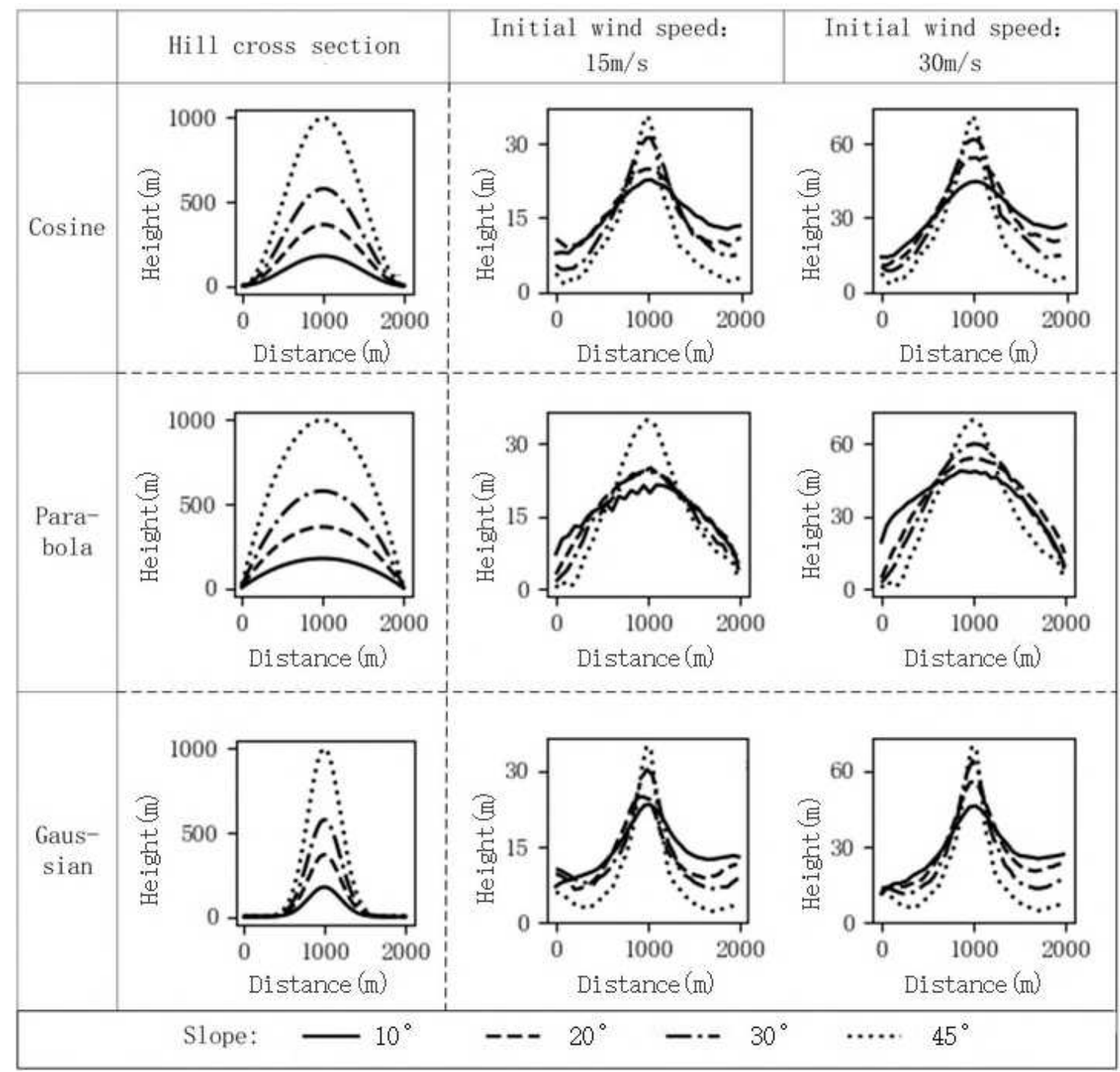

Figure 2. CFD mountain wind speed simulation results

At the peak and foot of the mountain, the results show that under the two input wind speed conditions, the wind speed significantly changes when the height of the mountain increases and decreases. The wind speed significantly increases when the wind approaches the apex of the three types of mountains; when the total length of the mountain is identical, a greater a slope of the mountain (a larger height) corresponds to a more obvious increase in wind speed at the apex. At the foot of the windward slope and leeward slope, the wind speed decelerates, and the deceleration amplitude is related to the slope. 
A greater slope corresponds to a more obvious deceleration. When the slope of the mountain exceeds $16^{\circ}$ $(\tan \alpha>0.3)$, the trend of wind speed changing with the mountain does not change, which is similar to the law of the overall wind speed of a mountain with a slower slope.

On the hillside, the wind speed distribution on the windward and leeward slopes is closer to the top of the mountain and exhibits a symmetrical shape. Outside of its scope, the two wind speed distributions are different: the wind speed shows an overall increasing trend from the foot of the windward slope to the top of the mountain, and only the Gaussian mountain first decreases and subsequently increases when the slope is large. The wind speed at the foot of the leeward slope tends to rise; i.e., the wind speed on the leeward slope first decreases and subsequently increases. However, in most cases, the magnitude of the change is small, and the change is more obvious only when the slope exceeds $30^{\circ}$.

On the whole, the distribution of wind speed is very similar to the shape of the mountain itself; i.e., the terrain correction factor is not simply a continuous linear change with the distance of the peak of the mountain but changes with the shape of the mountain.

\subsubsection{CFD-based terrain factor}

Based on 24 sets of wind speed simulation results performed by CFD, quantitative analysis was performed, and the wind speed change characteristics were extracted from a statistical viewpoint. For the foot of the windward slope and the foot of the leeward slope, we selected the minimum wind speeds that occurred in these two areas, calculated the ratio of the input wind speed, i.e., the terrain correction coefficient $(\eta)$, and combined $\eta$ with the slope, mountain height and other variables. The fitting was performed, and the calculation formula of the terrain correction coefficient was obtained. For mountain apexes, the existing correction method can reflect the characteristics of wind speed changes within its scope of application. Based on the characteristics, setting the slope correction coefficient provides a more detailed correction plan for mountains with slopes greater than $17^{\circ}(\tan \alpha>0.3)$. Since the difference in wind speed is affected by different mountain shapes, the calculation method of $\eta$ on the slope is changed to vertical interpolation to highlight the difference in influence of different mountain shapes on the wind speed and make it closer to the real wind speed distribution. Due to the shielding effect of the mountain, the wind speed in the flat area behind the leeward slope of the mountain maintains a deceleration trend of a certain distance. The specific calculation method is shown in Table 1:

Table 1 Redefinition $\eta$ calculation method based on CFD

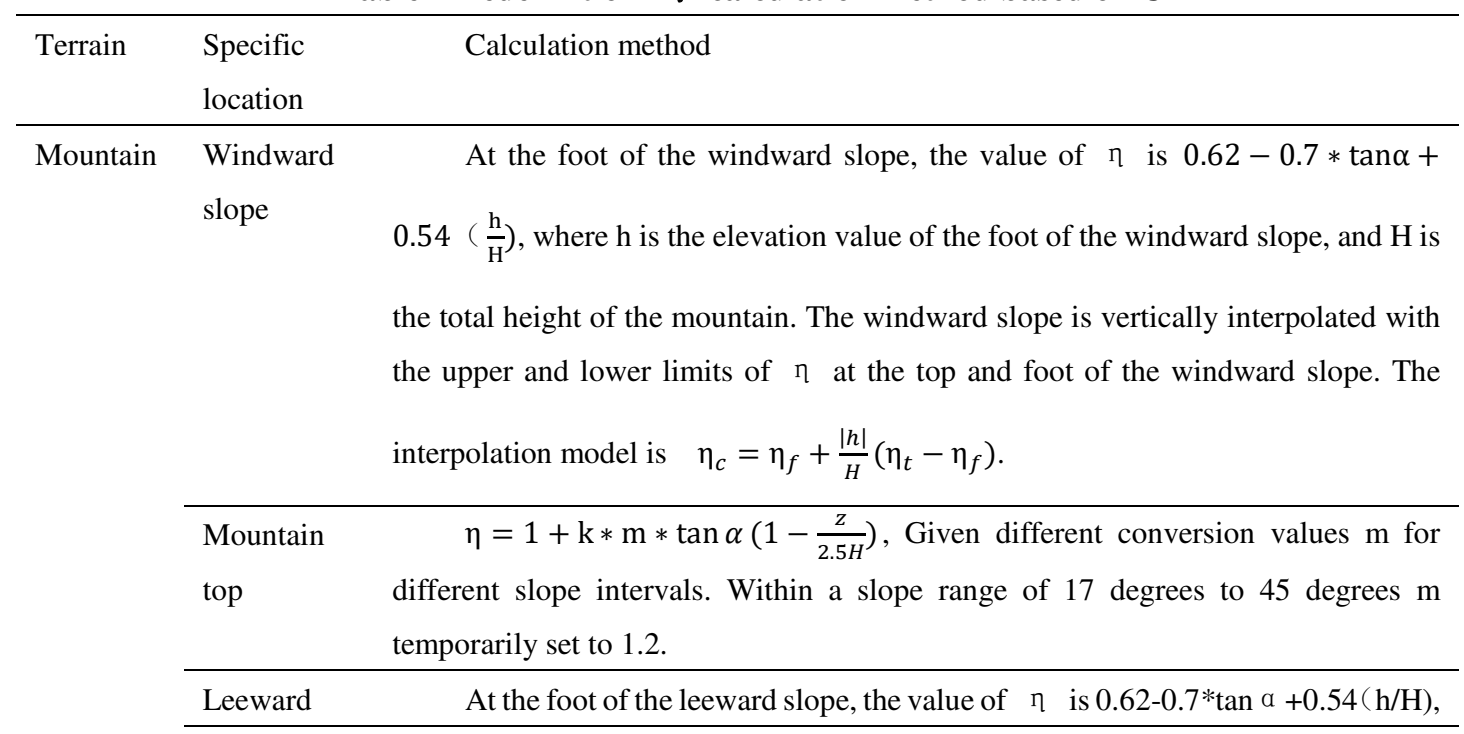




\begin{tabular}{|c|c|c|}
\hline & slope & $\begin{array}{l}\text { Vertical interpolation is still used on the slope. It needs to be pointed out that the } \\
\text { wind speed at the foot of the leeward slope has a small rise, which is ignored for } \\
\text { simplified calculations on a large scale. }\end{array}$ \\
\hline $\begin{array}{l}\text { Affected } \\
\text { area }\end{array}$ & $\begin{array}{l}\text { Downwind } \\
\text { area }\end{array}$ & $\begin{array}{l}\text { From the foot of the leeward slope to the downwind area approximately } 15 \\
\text { times the height of the mountain (Cheng } \mathrm{H} \text { et al. 2015), the correction coefficient } \\
\text { gradually rises to } 1 \text {, which means it is out of the influence of the terrain. }\end{array}$ \\
\hline
\end{tabular}

In addition to the mountain terrain in Table 1, for other undulating terrains such as canyons and basins, refer to the recommended values in the "Building Structure Load Code".

\subsection{Simulation of near-surface typhoon wind field}

\subsubsection{Typhoon wind field simulation results}

The near-surface wind field of Typhoon "Weipa" (ID is 0713) was simulated using the gradient wind field model, boundary layer model and terrain factor calculation model modified by CFD. The result is shown in Fig. 6. A higher wind speed occurred near the typhoon landing point in Cangnan County and Pingyang County in southern Zhejiang Province at $75.42 \mathrm{~m} / \mathrm{s}$. This area is near the typhoon landing center, the terrain is relatively undulating, and the buildings are relatively sparse, which further increases the near-surface wind speed of the typhoon. The area with lower wind speed is located in the western part of Shandong Province. When the typhoon center passes through this area, the intensity is already weak. The area is inland, flat and densely populated with cities and towns, which further decreased the near-surface wind speed of the typhoon. 


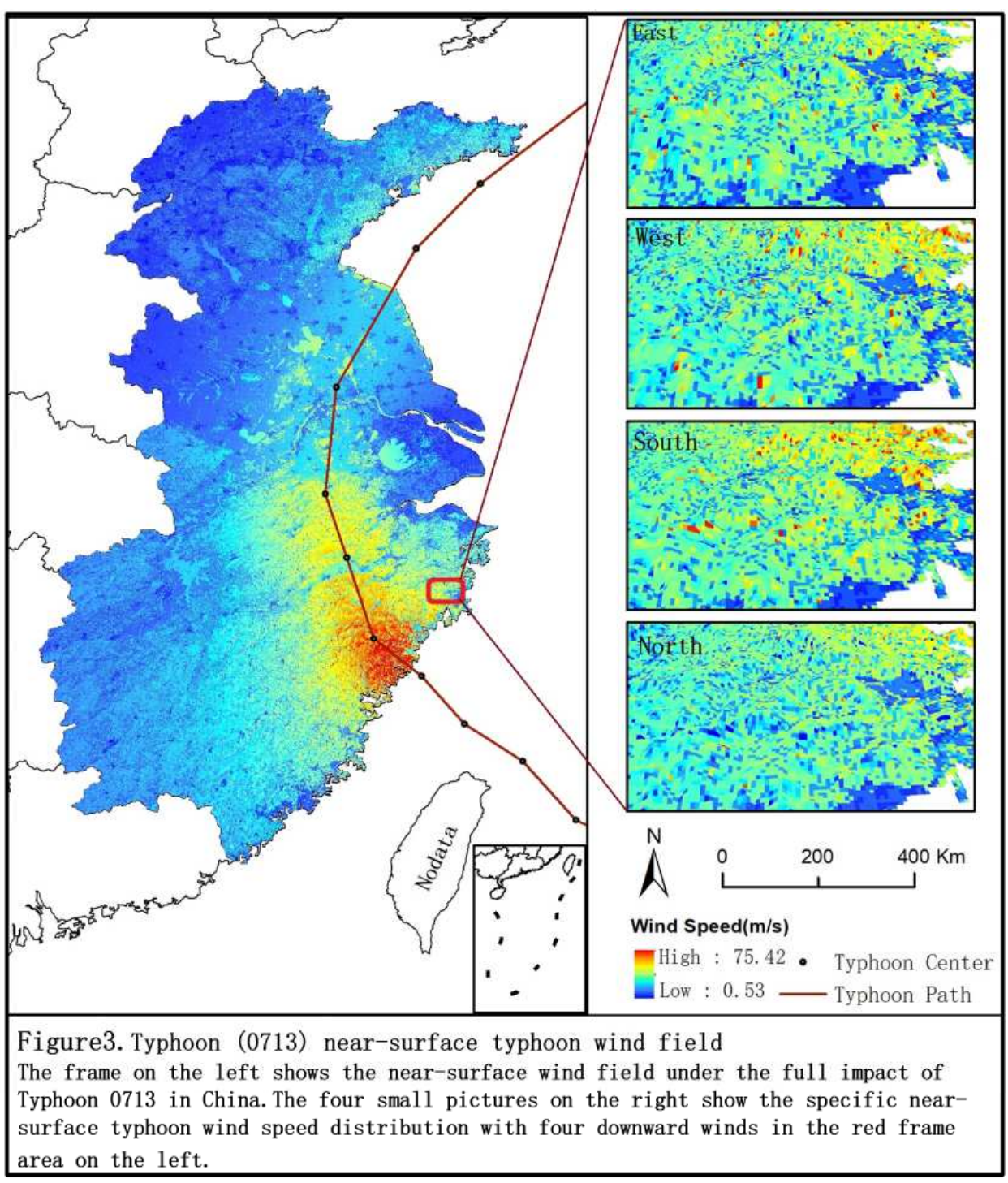

To verify the simulation effect of the CFD-based wind field model, the wind speed recorded at 499 stations and the simulation results during the duration of typhoon 0713 were used for point-to-point verification, and there were 487 valid data points. The maximum absolute difference between the CFDbased typhoon wind field model simulation results and the actual wind speed measured by the weather station is $15.2 \mathrm{~m} / \mathrm{s}$, and the minimum is $0.15 \mathrm{~m} / \mathrm{s}$. The average error rate of all weather stations is $26.6 \%$, and the variance of the error rate is 5.3. To verify the effect of the CFD-corrected terrain factor calculation model on the simulation accuracy, the results of various commonly used models are further compared, as shown in Table 2 .

Table 2 Verification and comparison of the wind field simulation results

\begin{tabular}{lccc}
\hline \multicolumn{1}{c}{ Models } & $\begin{array}{c}\text { Absolute value of maximum wind } \\
\text { speed difference }(\mathbf{m} / \mathbf{s})\end{array}$ & $\begin{array}{c}\text { Average error } \\
\text { rate }(\boldsymbol{\%})\end{array}$ & $\begin{array}{c}\text { Error } \\
\text { variance }\end{array}$ \\
\hline Gradient wind field model & 45.76 & 100.4 & 79.76 \\
Typhoon wind field model ignoring & 28.1 & 46.5 & 34.2
\end{tabular}


the influence of terrain (Holland G J

2008)

Typhoon wind field models based on

building codes (Building Structure

Load Code 2012)

Typhoon Near Surface Wind Field

Based on CFD

Compared with the simulation results that ignore the terrain and the commonly used simulation results, the average error rate of the CFD-based typhoon wind field model has decreased by $19.9 \%$ and $15 \%$, and the absolute difference of the maximum wind speed has decreased by $46 \%$ and $33 \%$.

To further explore the simulation effect of the wind field model based on CFD, Zhejiang Province with undulating terrain, Jiangsu Province with mainly flat terrain, and Shandong Province with balanced terrain are separately selected for the wind speed analysis. The measured wind speed and simulated wind speed of the weather stations are compared in Figure 4.

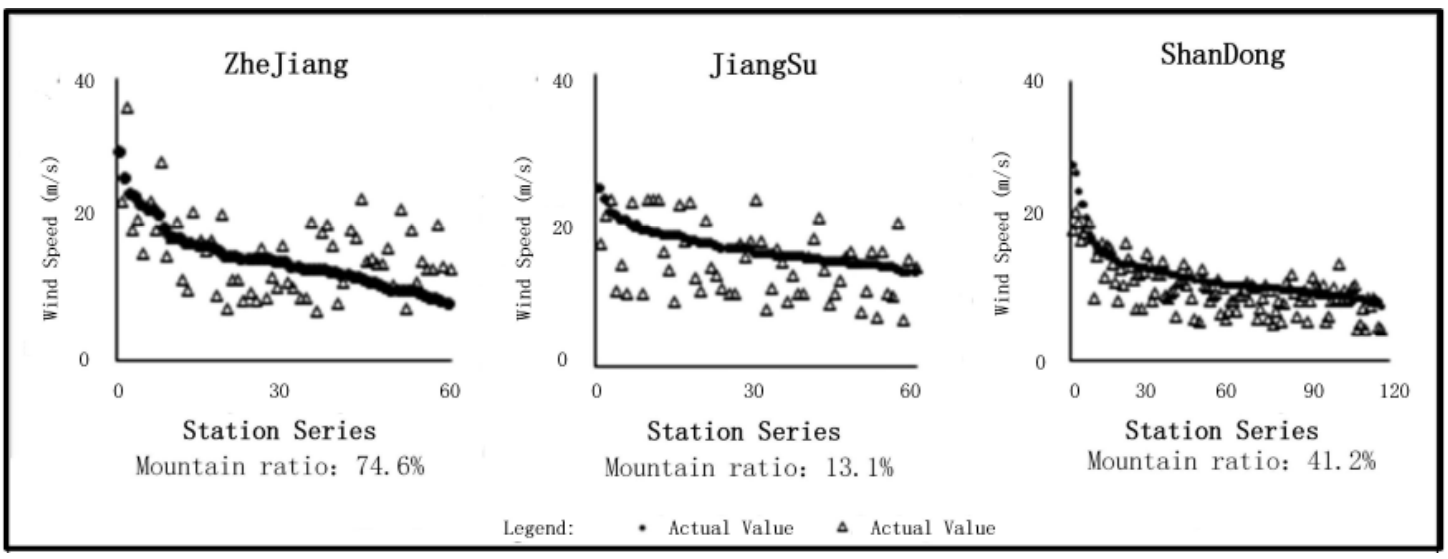

Figure 4. Typhoon (0713) near-surface typhoon wind field

Taking topography as the main difference factor for analysis, the average error rate of 62 meteorological stations in Zhejiang Province is 39\%. Compared with other models with error rates of $111.2 \%$ and $90.23 \%$, the simulation accuracy is significantly improved, but the overall error rate is relatively high within the range of typhoon 0713. Based on the analysis of DEM data and land use data, the main errors of Zhejiang's internal wind speed simulation appear in the mountainous areas of western Zhejiang, mainly in mountain basins and canyons, which indicates that the existing CFD-based typhoon wind field model is insufficient for the correction of blocked terrain. For Jiangsu and Shandong provinces, where the terrain is flat and the terrain is relatively balanced, the simulation errors are $21.4 \%$ and $18.9 \%$, respectively, which are better than the simulation results of all affected areas.

For the entire process of typhoon 0713, the intensity of the typhoon successively decreases in Zhejiang, Jiangsu and Shandong. In Zhejiang, where the typhoon intensity is strong, the absolute value of the wind speed is relatively large, and a small change in topographical influence factor will worsen the simulation results. With large changes, the error distribution between simulation results and the true value is more scattered than the distribution in the other two provinces. In Jiangsu and Shandong provinces, where typhoons are weaker, they are more concentrated. 


\section{Discussion}

Mainly consider the influence and effect of terrain correction on large-scale typhoon wind field simulation. Therefore, in the process of simulating wind speed of typical terrain through CFD, only one common roughness parameter suitable for common land use types is used, and the influence of complex roughness on wind speed is not considered. .

Compared with other models, the simulation accuracy of the results of the method in this paper is greatly improved in mountainous areas and areas with high terrain complexity, but the error in areas with relatively flat terrain remains high. On one hand, the CFD-based terrain correction factor is more applicable to areas with large terrain undulations than the usual correction methods; on the other hand, the influence of the terrain on the wind speed in real situations is very complicated, such as the mutual influence between mountains.

Other possibilities for errors include the following: areas dominated by plains may be more susceptible to the roughness of different land use types. In the gradient layer wind field model, when the typhoon center pressure is high and the typhoon intensity is weak, the wind speed simulation value tends to be low.

In general, the simulation results of the typhoon wind field model based on the CFD terrain correction can accurately reflect the spatial difference and range of typhoon wind hazard factors, which are greatly improved compared to the conventional typhoon wind field model, especially when the terrain is undulating. The area is more significant. The results of this paper can provide technical support or reference for typhoon disaster risk assessment, loss risk assessment and its application.

\section{Conclusion}

After using CFD to perform large-scale typhoon wind field simulation and calculation, we find problems such as overestimation or underestimation of the wind speed in the terrain correction method referring to the building wind load specification. This thesis combines the advantages of CFD simulation of a small-scale complex terrain wind speed field with the calculation characteristics of a large-scale terrain correction method in wind load. We also propose a large-scale complex terrain correction method to simulate the near-surface typhoon wind field. The main conclusions are as follows:

1) Based on CFD to simulate the wind field distribution of small-scale terrain with 4 different shapes, 4 different slopes, and 2 initial wind speeds, the wind speed distribution at the peak and foot of the mountain is directly related to the slope of the mountain, and the wind speed distribution on the slope shows similar regularity.

2) CFD simulation results for typical topographic data for statistical analysis show that the windward foot summit point, which is characterized in leeward wind speed corresponding to the foot of the topographical features, yields better indicator fitting results. Compared with the terrain correction method in the building structure load code, the method in this paper can more accurately express the wind speed distribution and changes.

3) For typhoon wind field terrain correction based on CFD simulation, a larger scale wind field can characterize the spatial distribution and intensity differences and more substantially improve the simulated near-surface region of the wind typhoon. Compared with the simulation results of the typhoon wind field that ignores the influence of terrain and load codes, the accuracy improves by $19.9 \%$ and $15 \%$, respectively. 
Funding: This research was funded by the National Key Research and Development Program of China, grant numbers 2017YFA0604903 and 2017YFA0604904, which are funded by the Ministry of Science and Technology of the People's Republic of China.

\section{References}

[1] Fang Weihua, Lin Wei. Summary of Research on Typhoon Wind Field Models for Disaster Risk Assessment [J]. Geographical Science Progress,2013,32(06):852-867. (in Chinese)

[2] Li Qian, Duan Zhongdong. Shapiro Typhoon Wind Field Model and Its Numerical Simulation [J]. Journal of Natural Disasters,2005(01):45-52. (in Chinese)

[3] Ou Jinping, Duan Zhongdong, Chang Liang. Analysis of Typhoon Hazard in Key Cities along the Southeast Coast of China [J]. Journal of Natural Disasters,2002(04):9-17. (in Chinese)

[4] Alexander D. Confronting Catastrophe - New Perspectives on Natural Disasters[M]. Oxford University Press, 2000.

310 [5] Ngo T T , Letchford C W. Experimental study of topographic effects on gust wind speed[J]. Journal of Wind Engineering and Industrial Aerodynamics, 2009, 97 (9-10):426-438.

[6] Maharani Y N, Lee S, Lee Y-K. Topographic effects on wind speed over various terrains: A case study for Korean Peninsula[C]. The Seventh Asia-Pacific Conference on Wind Engineering. Taipei, 2009.

[7] Building Structure Load Code [S]. GB50009-2012. 2012.(in Chinese)

[8] Takanori Uchida. Computational Fluid Dynamics Approach to Predict the Actual Wind Speed over Complex

[9] Kang Shun, Wei Huirong. Discussion on the Feasibility of Applying CFD to the Prediction of Wind Speed Distribution in Wind Farms [J]. Journal of Engineering Thermophysics, 2009,29 (12:2400-2042)

[10] GRIFFITHS A, MIDDLETON J. Simulation on Separated flow over two-dimensional hills[J]. Journal of Wind Engineering and Industrial Aerodynamics,2010,98(3:155-160) building with a refuge floor[J]. International Journal of Computational Fluid Dynamics,2005,19(7):

[12] Chen Ping. Numerical study on the influence of terrain on the wind field in mountainous hills[D]. Zhejiang University, 2007.

[13] ISHIHARA T, HIBI K, OIKAWA S.A wind tunnel study of turbulent flow over a three-dimensional steep hill [J] . Journal of Wind Engineering and Industrial Aerodynamics, 1999, 83:95-107.

[14 ]LI Z L, WEI Q K, SUN Y. Influences of mountain topography on re-sponse to wind induced vibration of transmission tower $[\mathrm{J}]$. Power System Technology, 2010, 34 (11) :214-220. (In Chinese) [15] SHEN G H, YAO D, LOU W J, et al. Investigation of the wind field characteristics on Isola -ted hill and two adjacent hills using CFD numerical simulation $\quad[\mathrm{J}]$. Journal of Hunan University（Natural Sciences）, 2016, 43 (1) :37-44. (In Chinese) [16] Dong L, Li J Z, Xu Y J, Yang Y T, Li X M, Zhang H. Study on the Spatial Classification of Construction Land Types in Chinese Cities: A Case Study in Zhejiang Province[J]. Land,2021,10(5): hillside [J] . Journal of Hunan University（Natural Sciences），2016，43（3）:23-31. (In Chinese) [18] Holland G J. 1980. An analytic model of the wind and pressure profiles in hurricanes. Monthly Weather 
Review,1 08(8): 1212-1218.

338 [19] Lin Wei, Fang Weihua. Research on the Regional Characteristics of Holland B Coefficient in the Northwest 339 Pacific Typhoon Wind Field Model [J]. Tropical geography, 2013,33(02):124-132.(in Chinese)

340 [20] Vickery P J, Dhiraj W. Statistical models of Holland pressure profile parameter and radius to maximum 341 winds of hurricanes from flight-level pressure and $\mathrm{H}^{*}$ Wind data[J]. Journal of Applied Meteorology and 342 Climatology, 2008, 47 (10): 2497-2517.

343 [21] LOU W J, LIU M M, LI Z H, et al.Research on mean wind speed characteristics and speed-up effect in 344 canyon terrain $[\mathrm{J}]$. Journal of Hunan University （Natural Sciences），2016，43 (7):8-15. (In Chinese)

346 [22] Cheng H, He J, Xu X, Zou X, Wu Y, Liu C, Dong Y, Pan M, Wang Y, Zhang H. 2015.Blown sand motion 347 within the sand-control system in the southern section of the Taklimakan Desert Highway. Journal of Arid Land, 348 7(5):599-611.

349 [23]Holland G J. 2008. A revised hurricane pressure-wind model. Monthly Weather Review,1 36(9): $3503432 \cdot 3445$. 


\section{Supplementary Files}

This is a list of supplementary files associated with this preprint. Click to download.

- WindSpeed15.xlsx

- Windspeed30.xlsx 